\title{
Como mestrandos agem retoricamente quando precisam justificar suas pesquisas
}

\section{How master students act rhetorically when they need to justify their research}

Francisco Alves Filho*

Universidade Federal de Piauí

Teresina, Piauí / Brasil

RESUMO: Objetivamos aqui analisar a organização retórica da seção de justificativa de pré-projetos de pesquisa de autoria de egressos de cursos de letras em situação de submissão a cursos de mestrado. A análise revelou a presença de quatro passos retóricos novos ainda não descritos para a seção de justificativa, bem como a recorrência de passos retóricos típicos de seções de objetivos, referencial teórico, metodologia, discussão e conclusão. Uma implicação pedagógica importante da pesquisa relaciona-se às funções da leitura voltadas para o universo da pesquisa. Os dados sugerem a prevalência de práticas de leitura voltadas para a compreensão de conceitos e para a explicação de fenômenos e, em contrapartida, são mais escassas as práticas de leitura focadas no desconhecido e nas lacunas de pesquisa.

PALAVRAS-CHAVE: seção de justificativa; organização retórica; projetos de pesquisa.

\begin{abstract}
We target here to analyze the rhetorical organization of the justificative section of pre-research projects of authorship of graduates of cursos de letras in a situation of submission to master's degree courses. The analysis displayed the presence of four new rhetorical steps not yet described for the justification section, as well as the recurrence of rhetorical steps typical of the sections of objective, theoretical framework, methodology, discussion and conclusion. An important pedagogical implication of the research is related to the reading functions directed to the research universe. The data suggest the prevalence of reading practices aimed at the understanding of concepts and the explanation of phenomena, and, in contrast, the reading practices focused on the unknown and on the research gaps are scarcer.
\end{abstract}

KEYWORDS: justification section; rhetorical organization; research project.

*chicofilhoo@gmail.com 


\section{Introdução}

O projeto de pesquisa é um gênero bastante relevante nos contextos acadêmico e de pesquisa pelo fato de funcionar como uma porta de acesso para financiamento de pesquisa, como requisito para ingresso em cursos de pós-graduação, para fortalecimento de programas de pós-graduação, além de poder ser tomado como um indicador de habilidades técnicas dos pesquisadores. $\mathrm{O}$ fato de os pesquisadores serem cada vez mais premidos a conseguir financiamento para seus trabalhos indica o quão relevante se apresentam os projetos de pesquisa, uma vez que o seu financiamento depende crucialmente da capacidade do pesquisador de elaborar um projeto. Contudo, mesmo em lugares com uma tradição consolidada em trabalhos acadêmicos, como os Estados Unidos, o interior da União Europeia e países asiáticos, os projetos têm recebido menos atenção do que os artigos de pesquisa (TSENG, 2011). No Brasil, o cenário não é diferente, havendo poucos estudos sobre esse gênero (BARROS, 2005; LEITÃO, 2008, MOTTA-ROTH; HENDGES, 2010; SILVA, 2015), com poucos deles tendo como objeto de estudo projetos submetidos à seleção de pós-graduação (JUCÁ, 2006; MONTEIRO, 2016; RIO LIMA, 2015; SILVA, 2015).

Grande parte dos programas de pós-graduação da área de letras e linguística no Brasil utilizam como uma das etapas de seus processos seletivos a apresentação e a defesa de um projeto de pesquisa, o qual é também designado como pré-projeto, anteprojeto, projeto de dissertação. No geral, os candidatos se mostram um tanto inseguros nessa etapa, seja pela falta de experiência com elaboração seja pela falta de acesso a projetos autênticos, ou mesmo pelas orientações vagas contidas em muitos editais e manuais de metodologia científica e/ou de escrita de projetos.

Ao fazer uma sistematização dos principais estudos existentes sobre projeto de pesquisa, Tseng (2011) reúne as investigações em três grupos. Do primeiro deles fazem parte os trabalhos baseados na noção de movimento retórico que visam descrever a organização retórica do gênero em termos funcionais (BHATIA, 2004; CONNOR; MAURANEN, 1999; SWALES, 1990, 2004). O segundo grupo - a exemplo de Feng e Shi (2004), Connor e Upton (2004), e Feng (2008) - adota a perspectiva da linguística de corpus para descrever distribuição, frequência e variação de traços linguísticos de projetos de pesquisa autênticos. Distanciando-se metodologicamente dos dois grupos anteriores, o terceiro mantém o foco sobre uma dimensão 
sociocognitiva, buscando compreender as práticas sociais incorporadas no sistema de gêneros do qual faz parte o projeto de pesquisa, como é o caso dos trabalhos de Tardy (2003) e Tseng (2011). Este último analisa os projetos de pesquisadores de universidades tanto do ponto de vista dos produtores quanto do ponto de vista dos interlocutores. Embora tenha encontrado a presença de movimentos retóricos estereotipados nas propostas de submissão, a pesquisa advoga em prol da relevância de se estudar a complexidade envolvida na caracterização e leitura deste gênero. Tal complexidade exigiu a formulação de mais duas metáforas para definir gênero: gênero como luta (entre o pesquisador e as instituições de fomento, entre o pesquisador e seus colegas pareceristas, e luta interna do próprio autor do projeto) e gênero como performance.

Em face das questões empíricas e teóricas apontadas, o objetivo deste artigo é analisar a organização retórica da seção de justificativa do gênero pré-projeto de pesquisa, correlacionando-a aos modos de funcionamento do gênero, num corpus de projetos de mestrandos aprovados em processos seletivos na área de Linguística, numa universidade pública brasileira.

\section{Retórica de projetos de pesquisa}

Myers (1985 apud TARDY, 2003) conclui de seu trabalho sobre projetos de pesquisa produzidos por dois biólogos que toda sentença nos exemplares de texto analisados visa persuadir, embora essa persuasão não seja ostentatória, ou o escritor busque persuadir "sem parecer persuadir". Tardy (2003, p. 7) entende que esse tipo de persuasão tem um caráter bastante complexo, sendo essa complexidade materializada nos textos em duas circunstâncias: a) quando os autores apresentam seu trabalho "como original, mas intimamente relacionado às preocupações de pesquisa atual; b) quanto se afirmam como pesquisadores num formato, sintaxe e personalidade que opera contra tal autoafirmação". Vemos aí duas características aparentemente contraditórias: primeiro, considera-se que a originalidade deve se ancorar na tradição e no status quo da pesquisa atual e, segundo, a autoafirmação tem que se valer de um estilo de escrita que tende para o impessoal. Certamente, essa dualidade dos projetos desafia e torna complexa e difícil a aprendizagem de jovens pesquisadores, já que são impelidos pelo gênero a propor novidades legitimadas pelas tradições de cada território de pesquisa, precisando aproximar características essencialmente diferentes e, até certo ponto, contraditórias. 
Connor e Mauranen (1999, p. 47-48) também defendem que os projetos de pesquisa podem ser considerados como um tipo de escrita persuasiva, já que eles visam convencer os pareceristas e as agências de fomento a financiar a proposta apresentada. Os pré-projetos de pesquisa submetidos à seleção de pós-graduação também compartilham essa natureza geral persuasiva, nesse caso visando persuadir a banca examinadora de que a proposta atende ao edital e às linhas de pesquisa do programa e oferece indícios de que o seu autor possui mérito acadêmico para ingressar num curso de pós-graduação.

Outro aspecto bastante interessante nos projetos de pesquisa relaciona-se ao lugar que o pesquisador precisa ocupar em relação aos consensos no seu campo do conhecimento (MYERS, 1985 apud TARDY, 2003). Ou seja, há aqui um dilema de difícil resolução pois um projeto de pesquisa precisa revelar lacunas numa área de pesquisa, mas o pesquisador não pode criticar abertamente a tradição da área. É como se o projeto, simultaneamente, devesse prestar deferência e desconfiança em relação às pesquisas anteriores. Ao mesmo tempo, o proponente precisa enunciar como um membro típico e engajado na área, mas deve dela se distanciar para revelar suas possíveis falhas. Uma estratégia para lidar com esta complexidade enunciativa é se amparar nas citações, tendo em vista que a "citação das fontes é uma estratégia usada para enfrentar o difícil equilíbrio entre identificação de grupo e autoafirmação" (CONNOR; MAURANEN, 1999 , p. 49). Contudo, nos projetos de pesquisa de mestrandos aqui analisados, as citações não revelam tensão entre o pesquisador e a área de pesquisa. Ao contrário, as citações, no geral, revelam homologação das ideias dos autores, o que, hipoteticamente, pode ser tomado como um indício da dificuldade de apropriação do caráter dual dos projetos em termos de crítica e continuidade das tradições de pesquisa.

A complexidade retórica, discursiva e textual dos projetos de pesquisa contribui para que sua aprendizagem se reverta em um processo difícil e, no geral, duradouro. Essa é a visão de Myers (1985 apud TARDY, 2003), o qual sustenta que um pesquisador aprende a retórica de área de pesquisa durante a graduação e a pós-graduação e continua aprendendo durante toda a sua vida de pesquisador por meio dos pareceres recebidos sobre suas submissões. Nesse ponto, os candidatos a cursos de pós-graduação ficam em desvantagem quanto às oportunidades de aprendizagem tendo em vista que a maioria dos processos seletivos no Brasil não envia ao candidato 
um parecer justificando a avaliação atribuída ao projeto submetido. Ou seja, não há feedback sobre a avaliação do projeto, o que impede, em parte, o reconhecimento, por parte de novos pesquisadores, dos valores, crenças e epistemologias que promulgam o reconhecimento e aprovação institucional de projetos de pesquisa, quando isso é fundamental para a aprendizagem dos gêneros (BERKENKOTTER; HUCKIN, 1995).

Connor e Mauranen (1999) entendem que os projetos de pesquisa compartilham propósitos, movimentos retóricos e características linguísticas com os artigos de pesquisa, sobretudo em relação à seção de introdução destes últimos. A despeito dessas semelhanças, observam que os projetos possuem características próprias diretamente relacionadas a movimentos retóricos específicos do gênero, como realizações, benefícios, importância e condescendência, os quais possuem em comum o fato de "projetarem uma imagem positiva da pesquisa pretendida" (CONNOR; MAURANEN, 1999, p. 61).

Há um reconhecimento por parte de muitos estudiosos de que o projeto de pesquisa é fortemente integrado a um sistema de gêneros, tal como conceituado por Bazerman (2005, p. 32). ${ }^{1}$ O estudo de Connor (2000), por exemplo, sugere que os autores de projetos de pesquisa necessitam conhecer uma multiplicidade de gêneros, sendo que esses por sua vez situam-se em comunidades discursivas por vezes distintas. Na mesma linha de raciocínio, Tardy (2003, p. 31) defende que "o projeto de pesquisa é somente uma pequena parte do sistema intertextual mais amplo envolvendo múltiplos grupos". Através de depoimentos de pesquisadores experientes, Tardy percebeu que o processo de escrita de projetos de pesquisa é complexo e longo e envolve diversos tipos de interações e a participação em comunidades científicas. Uma das formas de mitigar a complexa aprendizagem de gêneros institucionais tem sido a descrição da organização retórica de tais gêneros, visando oferecer uma fotografia dinâmica de como tipicamente os escritores elaboram os textos em termos umbilicalmente formais e funcionais. Em parte, a pesquisa aqui relatada busca oferecer respostas para essa necessidade ao propor descrever a organização retórica da seção de justificativa de pré-projetos.

\footnotetext{
${ }^{1}$ Bazerman (2005, p. 32) defende que os sistemas de gêneros são "os diversos conjuntos de gêneros utilizados por pessoas que trabalham juntas de uma forma organizada, e também as relações padronizadas que se estabelecem na produção, circulação e uso desses documentos".
} 


\section{Organização retórica: propósitos, movimentos e passos}

O termo organização retórica costuma ser mais pressuposto pelos pesquisadores do que conceituado explicitamente. No geral, significa o modo como, de forma um tanto idealizada, mas decorrente de análise empírica, uma dada seção de um gênero se organiza em termos de movimentos e passos retóricos. Dito de outra forma, uma organização retórica busca oferecer um desenho de como, preferencialmente ou recorrentemente, os escritores numa dada comunidade discursiva organizam seus textos em termos funcionais e pragmáticos visando atingir certos propósitos comunicativos e retóricos. Neste desenho tem sido fundamental descrever os passos e movimentos retóricos mais recorrentes.

O movimento retórico tem sido concebido como uma unidade funcional (de caráter discursivo ou retórico), e não formal dos gêneros (SWALES, 2004, p. 229), sobretudo daqueles mais acentuadamente convencionalizados. Ele é descrito por um enunciado abstrato que representa resumidamente uma ação de linguagem convencional e recorrente numa mesma seção de um gênero. Trata-se de uma noção que recobre as inter-relações entre unidades formais, funcionais e retóricas, usadas convencionalmente para compor propósitos comunicativos (SWALES, 1981, 1990). Um movimento retórico não apresenta uma extensão definida a priori, mas em geral contém ao menos uma proposição com clara coerência interna (MAURANEN, 1993 apud CONNOR; MAURANEN, 1999).

A identificação dos movimentos retóricos está na dependência dos objetivos retóricos de um gênero (CONNOR; MAURANEN, 1999). Ou seja, deve-se preferencialmente partir do conhecimento geral acerca das funções que o gênero desempenha nos contextos sociais para postular movimentos retóricos associados a tais funções. Essa dependência do reconhecimento dos movimentos retóricos em relação às funções comunicativas globais do gênero indica quão complexa é tal tarefa, já que a identificação dos propósitos comunicativos de um gênero é também bastante complexa tendo em vista que nem sempre há consenso entre os especialistas e entre estes e os analistas de gênero acerca de quais sejam os propósitos de um gênero. Há ainda o fato de sujeitos com expertise conseguirem imiscuir propósitos particulares em meio aos propósitos mais gerais de um gênero (BATHIA, 2004); e alguns propósitos, embora identificados, nunca serem reconhecidos pelos sujeitos (ASKEHAVE; SWALES, 2009). Como os propósitos de um gênero podem não ser sempre evidentes, explícitos e dados a priori, a sua 
identificação poderá depender de uma investigação demorada, cuidadosa e dependente de várias metodologias de pesquisa. Com os movimentos retóricos ocorrerão processos similares, embora as pistas textuais possam auxiliar um pouco mais nessa tarefa.

Como os movimentos retóricos exibem as relações entre forma e função dos textos, as pistas linguísticas servem como elementos relevantes para o seu reconhecimento, embora precisem ser vistas também com desconfiança e cautela por parte do pesquisador, tendo em vista a própria opacidade da linguagem e os atos de fala indiretos na comunicação. Há um reconhecimento de que os elementos indicadores de fronteira entre segmentos textuais são bastante relevantes para o reconhecimento dos movimentos retóricos (CONNOR; MAURANEN, 1999, p. 51). Connor (2000, p. 8) descobriu que, embora os projetos de pesquisa compartilhem um repertório de movimentos, "há uma grande variação na sequência dos movimentos e no âmbito para o qual certos movimentos são exigidos ou opcionais". No caso dos projetos de pesquisa aqui analisados, as sugestões de Connor e Mauranen podem ser parcialmente úteis em relação à identificação do propósito retórico geral, que é ter o projeto reconhecido como de qualidade e aprovado por uma banca de seleção. Entretanto, parece haver propósitos retóricos secundários não tão convencionais ou acordados entre os participantes. Quanto à segmentação do texto, também os pré-projetos apresentam dificuldades, embora as seções do texto sejam convencionadas e padronizadas pelos editais, já que nem sempre há claras pistas linguísticas no interior de cada seção que possam favorecer o reconhecimento dos movimentos retóricos.

Os estudos pioneiros sobre movimentos retóricos são aqueles que tomaram como objeto de estudos as introduções em artigos de pesquisa. Swales (1990) descobriu que um dos movimentos mais relevantes nessa seção se liga à maneira como os autores estabelecem nichos de pesquisa, ou seja, como tentam justificar o posicionamento adotado no estudo. Swales propôs uma estrutura contendo três principais movimentos: a) estabelecer um território, o qual inclui reivindicar centralidade, generalizar tópicos e revisar pesquisas anteriores; b) estabelecer um nicho, o qual inclui contra-argumentar, indicar uma lacuna, levantar uma questão e continuar uma tradição; c) ocupar um nicho. Tendo em vista as correlações de continuidade entre projeto e artigo de pesquisa, supomos aqui que alguns dos passos retóricos contidos nesses três movimentos das introduções 
de artigos de pesquisa também podem ser necessários ou esperados em projetos de pesquisa. Nestes, há a expectativa de que o autor revise trabalhos anteriores relacionados ao seu tópico de investigação, que contra-argumente posicionamentos teóricos diferentes dos que serão adotados, que indique lacunas em pesquisas anteriores, tendo em vista que um projeto de pesquisa tem como uma de suas principais funções oferecer soluções para lacunas de pesquisa existentes. Também é claramente justificável que um projeto de pesquisa vise levantar uma questão bem como busque continuar uma tradição de pesquisa, já que as comunidades científicas somente aprovam projetos claramente inseridos em tradições consolidadas de pesquisa.

Tendo em vista certas imprecisões conceituais que, por vezes, são feitas entre propósito comunicativo, movimento retórico e passos retóricos, faremos aqui uma proposta de distinguir teoricamente estes três conceitos. O propósito comunicativo corresponde à função retórico-comunicativa desempenhada por um gênero em contextos sociais delimitados, tendo como escopo um gênero particular, isto é, um tipo histórico de texto ou uma classe de textos, e, por isso, apresenta um acentuado grau de abstração em relação a textos particulares. Ele não diz respeito a uma sequência linguística delimitada e única, mas é abstraído a partir do uso recorrente de um mesmo gênero em situações também recorrentes, ou seja, pode não apresentar uma contraparte textual ou marcas linguísticas características. O propósito comunicativo depende de fatores extralinguísticos, como intenções, interações e processos cognitivos e, por isso, sua descrição depende do trabalho do analista ou de uma formulação explícita dos falantes. Possui um grau de abstração acentuado em relação à materialidade textual e, somado $\mathrm{a}$ isso, acentuada dependência contextual.

O movimento retórico indica uma função retórico-comunicativa relativamente padronizada desempenhada por agrupamentos de sequências textuais usadas em um gênero de texto particular ou em uma de suas seções. Mais comumente, o movimento retórico tem como escopo uma seção típica de um gênero. Não diz respeito a uma sequência linguística delimitada e única, mas a uma função retórica descrita por um analista com base em passos retóricos funcionalmente congruentes. Pode apresentar uma contraparte textual, mas esta, muitas vezes, é difusa do ponto de vista da estruturação textual. Seu reconhecimento depende de fatores extralinguísticos, como propósitos comunicativos, interações e processos cognitivos. 
O passo retórico (também chamado de estratégias e subunidades) é a função retórico-comunicativa desempenhada por uma sequência textual particular a qual, para gozar deste status, precisa ser recorrente numa seção típica de um gênero. Tem como escopo uma sequência textual que pode variar de uma oração a alguns parágrafos e que apresenta uma função retórico-comunicativa particular. Geralmente, apresenta uma contraparte textual precisa e localizável, mas o seu status retórico depende de uma formulação exterior concebida pelo modelo teórico. Em relação ao propósito comunicativo e ao movimento retórico, depende menos de fatores contextuais e é menos abstrata.

Tendo em vista o fato de que: a) o movimento retórico é uma categoria postulada pelo pesquisador a partir de uma generalização baseada em certa afinidade entre determinados passos retóricos; b) o passo retórico é uma categoria mais próxima da realidade retórica dos escritores de projetos; c) a teoria sociorretórica dá primazia para as práticas retóricas e para os modos como os próprios sujeitos concebem suas práticas, optamos nesta pesquisa por abandonar a noção de movimento retórico e fazer uso essencialmente da noção de passo retórico. O objetivo dessa opção é buscar reduzir, ao menos em parte, a interferência da visão do pesquisador sobre a conceptualização dos dados, processo muito marcante quando se faz uso da noção de movimento retórico. Além disso, deixando de seguir uma tradição presente na maioria das pesquisas da área, não faremos a distinção entre o caráter obrigatório ou não de passos retóricos (ao qual corresponde a estrutura e/ou). Essa decisão é decorrente de nossa percepção de que o rótulo de obrigatório somente poderia ser estabelecido se fosse possível fazer uma análise com todos os exemplares de um gênero, tarefa absolutamente impossível, além de a própria noção de relativa estabilidade dos gêneros não ser congruente com uma visão de obrigatoriedade para uma categoria genérica.

\section{Movimentos e passos retóricos em projetos de pesquisa}

Os movimentos retóricos de projetos de pesquisa são comumente induzidos pelos editais de seleção, os quais fornecem algumas indicações acerca das expectativas das bancas de seleção em relação ao tipo de informação que devem conter os pré-projetos. Como consequência, os autores de projetos tendem a agir retoricamente de modo a atender tais expectativas. 
Em sua pesquisa, Connor e Mauranen (1999, p. 53) identificaram dez movimentos regulares em projetos de pesquisa de pesquisadores experientes. $^{2}$

QUADRO 1 - Movimentos retóricos em projetos de pesquisa

\begin{tabular}{|c|c|}
\hline Movimentos & Descrição e função \\
\hline Território & $\begin{array}{l}\text { "Responsável por estabelecer 'o território no qual a pesquisa tomará } \\
\text { lugar', o qual pode ser um lugar do 'mundo real' (fora do espaço da } \\
\text { pesquisa) e/ou o território (disciplina ou esfera) de pesquisa" (p. 53). }\end{array}$ \\
\hline Lacuna & $\begin{array}{l}\text { Tem como função "apontar para uma omissão, falha ou problema no } \\
\text { território real ou de pesquisa, algo que precisa de uma intervenção ou } \\
\text { explicação" (p. 53). Corresponde ao que Swales chamou de estabelecendo } \\
\text { o nicho. }\end{array}$ \\
\hline Objetivo & $\begin{array}{l}\text { Expressa a finalidade geral da pesquisa e mantem uma relação direta com } \\
\text { a movimento da lacuna, de tal modo que o objetivo possibilite sanar o } \\
\text { problema indicado. }\end{array}$ \\
\hline $\begin{array}{l}\text { Meios ou recursos } \\
\text { (metodologia) }\end{array}$ & $\begin{array}{l}\text { Tem como função explicitar as estratégias (métodos, procedimentos, } \\
\text { seleção de material e sujeitos etc.) que serão usadas para se atingir os } \\
\text { objetivos tragados. No geral, há uma conexão direta entre lacuna, objetivo } \\
\text { e meios, já que há a expectativa de que os meios permitam atingir os } \\
\text { objetivos tragados para sanar as lacunas. }\end{array}$ \\
\hline $\begin{array}{l}\text { Reportando pesquisa } \\
\text { previa }\end{array}$ & Tem como função relatar pesquisas anteriores no campo de pesquisa. \\
\hline Realizações & Apresenta, prospectivamente, os resultados ou descobertas esperadas. \\
\hline Benefícios & $\begin{array}{l}\text { Envolvem a utilidade e o valor dos resultados do estudo seja para o } \\
\text { mundo "real" ou para o mundo da própria pesquisa. }\end{array}$ \\
\hline $\begin{array}{l}\text { Reivindicação } \\
\text { de competência }\end{array}$ & $\begin{array}{l}\text { Contém informações sobre a qualificação, experiência e realizações do } \\
\text { grupo de pesquisadores. }\end{array}$ \\
\hline $\begin{array}{l}\text { Reivindicação } \\
\text { de importância }\end{array}$ & $\begin{array}{l}\text { Assevera que a proposta do projeto e de fato relevante, necessária ou } \\
\text { urgente seja para o mundo "real" ou para o universo da pesquisa. }\end{array}$ \\
\hline Condescendência & $\begin{array}{l}\text { Declaração de condescendência do projeto em relação aos objetivos da } \\
\text { agencia de fomento. }\end{array}$ \\
\hline
\end{tabular}

Fonte: estruturado a partir de descrição feita por Connor e Mauranen (1999).

${ }^{2}$ É curiosa a preferência dos autores por rotularem os movimentos retóricos com o uso de nomes e não como verbos no gerúndio, como fazem Swales e outros autores, já que os verbos de modo mais direto apontam para funções e propósitos ao passo que os nomes indicam mais estruturas e processos. 
A proposta apresentada trata como da mesma natureza seções do texto e movimento retórico, a exemplo de objetivos e meios. A nosso ver, objetivos e meios não são movimentos retóricos e sim seções dos textos dos projetos pelo fato de elas conterem em si vários movimentos e não indicarem exatamente quais ações retóricas são realizadas por seu intermédio. Ademais, objetivos e meios são nomes criados e consagrados pela prática de escrita de projeto, não resultando, portanto, de pesquisas que se ocupam em categorizar a movimentação retórica presente nos textos. Monteiro (2016), ao analisar a seção de metodologia de pré-projetos de pesquisa, defende convicentemente que esta seção é composta por quatro movimentos retóricos, sendo estes, por sua vez, estruturados por vários passos. Reduzir a seção de meios a um único movimento seria ofuscar uma série de aspectos retóricos e comunicativos bastante recorrentes nesta seção em projetos de pesquisa.

Uma descrição da organização retórica específica para a seção de justificativa é feita por Jucá (2006), conforme apresentada no Quadro 3, a qual resulta de uma adaptação do modelo CARS (SWALE, 1990), originalmente decorrente de análises de introduções de artigos de pesquisa. Jucá opta pelos termos unidade e subunidade correspondendo à categoria movimento passo na proposta inicial de Swales (1990).

QUADRO 2 - Padrão de organização retórica de seções justificativa de projetos de pesquisa

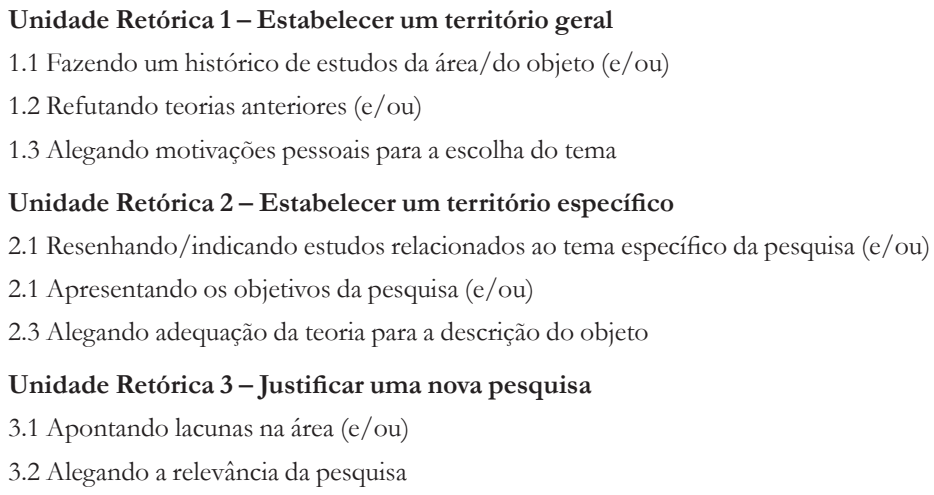

Fonte: Jucá (2006) 


\section{Metodologia}

Tendo em vista o objetivo deste artigo de analisar a seção de justificativa de pré-projetos de pesquisa de mestrandos aprovados em seleção para pós-graduação a nível de mestrado, tomou-se como amostra um corpus composto por trinta seções de justificativa. Os projetos foram submetidos e aprovados nos exames de seleção de pós-graduação dos anos de 2012, 2013 e 2014 e se enquadram nas subáreas de gramática, lexicografia, letramento, variação linguística, análise do discurso e linguística de texto. Os pré-projetos foram cedidos pelos mestrandos e fazem parte do banco de dados do projeto Propósitos comunicativos e movimentos retóricos em projetos de pesquisa na área de letras. Eles foram utilizados num contexto de seleção para alunos de pós-graduação em letras, na área de linguística, e se inserem num processo que inclui como etapas anteriores uma prova de proficiência em língua estrangeira, uma prova escrita de conhecimentos específicos e, como etapas subsequentes, uma arguição sobre o pré-projeto e a prova de títulos. Para ser considerado aprovado na etapa de análise do pré-projeto, o candidato precisa obter nota mínima 7,0. A comissão de seleção divulga apenas a nota do candidato no site da instituição de ensino superior, não sendo apresentadas justificativas ou comentários em relação ao desempenho do concorrente. Exige-se que os temas dos pré-projetos se insiram numa das linhas de orientação previamente divulgadas no site do programa bem como que haja a indicação prévia de dois orientadores pretendidos.

Foram excluídos da amostra os pré-projetos que não possuíam uma seção específica intitulada Justificativa e mantidos apenas os que possuíam esta seção e, do ponto de vista da estrutura textual, autônoma em relação às outras seções. Qualquer forma de identificação dos autores dos projetos foi subtraída dos dados de modo a se preservar o anonimato.

Os pré-projetos foram lidos na íntegra a fim de que a compreensão da proposta global fosse usada como guia geral para o reconhecimento dos passos retóricos. Posteriormente, a análise passou a focar a seção de justificativa e visou identificar ações de linguagem locais sendo realizadas em cada segmento do texto, mas essa identificação, em parte, foi motivada por movimentos retóricos já descritos antes (CONNOR; MAUNAREN, 1999; JUCÁ, 2006; MONTEIRO, 2016). Nos casos em que as ações de linguagem não coincidiam com movimentos ou passos já previamente descritos, levantaram-se hipóteses acerca da existência de novos passos retóricos. A 
fim de evitar um reconhecimento motivado por um alto grau de inferência da parte do analista, definiu-se que somente seriam reconhecidos os passos que contivessem pistas linguístico-textuais que funcionassem como indícios de algum ato ilocucionário, ${ }^{3}$ ou seja, de uma intenção pragmática pretendida. Em face disso, alguns segmentos textuais foram descartados pelo fato de não conter nenhum indício de ato ilocucionário.

Nos casos em que um passo apareceu mais de uma vez numa seção, e essa ocorrência tenha sido intercalada por outros passos, este passo foi computado mais de uma vez. Todos os passos encontrados foram catalogados num primeiro momento. em um segundo momento, operou-se com um corte de 16,6\% (ou 6 de um total de 30) de ocorrência em projetos diferentes, de modo que passos que ocorreram em menos de 16,6\% (ou 6 de um total de 30) dos pré-projetos foram descartados na análise final. Feita a catalogação dos passos retóricos, passou-se a analisá-los em conjunto para se avaliar quais passos eram congruentes entre si, no sentido de girarem em torno de aspectos tradicionalmente esperados para ocorrerem em seções de justificativa, como lacuna de pesquisa, relato de estudos prévios, relevância e benefícios da pesquisa, ou em outras seções como objetivos, discussão e conclusões.

Na discussão final faremos uma análise do significado e das implicações das escolhas retóricas presentes nos pré-projetos tendo como referencial o discurso de historiadores e filósofos da ciência sobre o fazer científico. O objetivo desta análise é observar até que ponto o discurso contido nos projetos se aproxima ou se distancia do discurso científico.

\section{Análise e discussão}

A análise das trinta seções, mantendo-se apenas os passos com recorrência superior a 16,6\% do total de trinta projetos, resultou num quadro com doze passos (Tabela 2), sendo que oito desses já haviam sido descritos em pesquisas anteriores, mesmo que para outras seções de projetos que não a justificativa. Os outros quatro passos retóricos que ainda não haviam sido

\footnotetext{
${ }^{3}$ Atos ilocucionários, segundo Austin (1990), correspondem àquilo que o falante pretende dizer com aquilo que diz, mesmo nos casos em que não há equivalência semântica entre o ato locucionário (aquilo que efetivamente foi dito do ponto de vista semântico) e aquilo que corresponde à intenção do falante.
} 
descritos para a seção de justificativa de projetos de pesquisa são: indicando indagações da pesquisa; recomendando e/ou prescrevendo ação empírica; definindo conceitos; e explicando um fenômeno.

QUADRO 3 - Passos retóricos da seção de justificativa e descrição correspondente

\begin{tabular}{|c|c|c|c|}
\hline Sigla & Passo & Descrição & Situação \\
\hline P1 & $\begin{array}{l}\text { Apresentando } \\
\text { objetivos da pesquisa }\end{array}$ & $\begin{array}{l}\text { Indica os objetivos gerais e/ou } \\
\text { específicos a serem perseguidos } \\
\text { durante a realização da pesquisa. }\end{array}$ & $\begin{array}{l}\text { Já descrito por Connor e } \\
\text { Mauranen (1999) e por Jucá } \\
\text { (2006). }\end{array}$ \\
\hline P2 & $\begin{array}{l}\text { Justificando a } \\
\text { relevância da pesquisa }\end{array}$ & $\begin{array}{l}\text { Apresenta argumentos que } \\
\text { servem para justificar a relevância, } \\
\text { necessidade ou impactos da } \\
\text { pesquisa. }\end{array}$ & $\begin{array}{l}\text { Já descrito por Jucá (2006) } \\
\text { e por Connor e Mauranen } \\
\text { (1999), pelo rótulo de } \\
\text { Reivindicação de } \\
\text { importância. }\end{array}$ \\
\hline P3 & $\begin{array}{l}\text { Relatando pesquisa } \\
\text { prévia }\end{array}$ & $\begin{array}{l}\text { Relata pesquisas recentes } \\
\text { (predominantemente nas últimas } \\
\text { duas décadas) enfocando as } \\
\text { contribuições destas em relação a } \\
\text { resultados, descobertas e propostas } \\
\text { de metodologia. Não inclui relato } \\
\text { em relação à contribuição teórica ou } \\
\text { conceitual. }\end{array}$ & $\begin{array}{l}\text { Já descrito por Connor e } \\
\text { Mauranen (1999). }\end{array}$ \\
\hline P4 & $\begin{array}{l}\text { Indicando possíveis } \\
\text { benefícios }\end{array}$ & $\begin{array}{l}\text { Indica quais benefícios ou } \\
\text { contribuições futuras poderão ser } \\
\text { adquiridos a partir dos resultados da } \\
\text { pesquisa. }\end{array}$ & $\begin{array}{l}\text { Já descrito por Connor e } \\
\text { Mauranen (1999). }\end{array}$ \\
\hline P5 & $\begin{array}{l}\text { Indicando problemas } \\
\text { do mundo real }\end{array}$ & $\begin{array}{l}\text { Menciona problemas na vida prática } \\
\text { (por exemplo em escolas, famílias, } \\
\text { universidades) que motivaram a } \\
\text { realização da pesquisa e que podem } \\
\text { ser solucionados ou atenuados com } \\
\text { os resultados da pesquisa. }\end{array}$ & $\begin{array}{l}\text { Já descrito por Connor e } \\
\text { Mauranen (1999) como } \\
\text { parte do movimento } \\
\text { lacunas, mas tendo sido } \\
\text { aqui tratado separadamente. }\end{array}$ \\
\hline P6 & $\begin{array}{l}\text { Indicando indagações } \\
\text { da pesquisa }\end{array}$ & $\begin{array}{l}\text { Apresenta uma ou várias perguntas } \\
\text { para as quais não há respostas } \\
\text { ou se tem respostas parciais e } \\
\text { inadequadas. Geralmente, aparecem } \\
\text { expressas de maneira diretamente } \\
\text { interrogativa, mas há casos em } \\
\text { que a indagação é formulada } \\
\text { indiretamente. }\end{array}$ & $\begin{array}{l}\text { Ainda não descrito em } \\
\text { pesquisas anteriores. }\end{array}$ \\
\hline
\end{tabular}




\begin{tabular}{|c|c|c|c|}
\hline P7 & $\begin{array}{l}\text { Delimitando corpus e/ } \\
\text { ou fonte do corpus da } \\
\text { pesquisa }\end{array}$ & $\begin{array}{l}\text { Passo de natureza tipicamente } \\
\text { metodológica, indica quais } \\
\text { elementos ou sujeitos irão compor o } \\
\text { material de análise da pesquisa. }\end{array}$ & $\begin{array}{l}\text { Já descrito por Connor e } \\
\text { Mauranen (1999), estando } \\
\text { incluído no movimento } \\
\text { meios. }\end{array}$ \\
\hline P8 & $\begin{array}{l}\text { Justificando a seleção } \\
\text { de corpus, fontes ou } \\
\text { sujeitos }\end{array}$ & $\begin{array}{l}\text { Passo de natureza tipicamente } \\
\text { metodológica, apresenta } \\
\text { justificativas usadas para presidir a } \\
\text { seleção das fontes e/ou sujeitos de } \\
\text { pesquisa. }\end{array}$ & $\begin{array}{l}\text { Já descrito por Connor e } \\
\text { Mauranen (1999), estando } \\
\text { incluído no movimento } \\
\text { meios. }\end{array}$ \\
\hline P9 & $\begin{array}{l}\text { Indicando lacuna da } \\
\text { pesquisa }\end{array}$ & $\begin{array}{l}\text { Indicação de algo que ainda não foi } \\
\text { estudado ou pesquisado em estudos } \\
\text { anteriores e permanece como } \\
\text { um campo aberto para uma nova } \\
\text { pesquisa. }\end{array}$ & $\begin{array}{l}\text { Já descrito por Connor e } \\
\text { Mauranen (1999) e por Jucá } \\
\text { (2006). }\end{array}$ \\
\hline P10 & $\begin{array}{l}\text { Recomendando e/ } \\
\text { ou prescrevendo ação } \\
\text { empírica }\end{array}$ & $\begin{array}{l}\text { Recomenda e/ou prescreve ações } \\
\text { pragmáticas a serem tomadas por } \\
\text { atores sociais (no geral educadores) } \\
\text { a fim de resolver ou atenuar } \\
\text { problemas da vida social. }\end{array}$ & $\begin{array}{l}\text { Ainda não descrito em } \\
\text { pesquisas anteriores. }\end{array}$ \\
\hline P11 & Definindo conceitos & $\begin{array}{l}\text { Passo de natureza eminentemente } \\
\text { teórica, centra em apresentar, } \\
\text { geralmente com apoio bibliográfico, } \\
\text { como determinadas categorias são } \\
\text { conceituadas na cultura disciplinar. }\end{array}$ & $\begin{array}{l}\text { Ainda não descrito em } \\
\text { pesquisas anteriores. }\end{array}$ \\
\hline P12 & $\begin{array}{l}\text { Explicando um } \\
\text { fenômeno }\end{array}$ & $\begin{array}{l}\text { Geralmente amparando-se em } \\
\text { fontes bibliográficas, são oferecidas } \\
\text { explicações para fenômenos } \\
\text { empíricos. Relata-se o que já se sabe } \\
\text { sobre determinados fenômenos, à } \\
\text { maneira como se faz isso sem seções } \\
\text { de discussão de resultados em } \\
\text { artigos. É muito semelhante ao } \\
\text { passo descrito por Nwogu (1990 } \\
\text { apud SWALES, 2004) para a seção } \\
\text { de discussão de artigos e que ele } \\
\text { denomina Explicando resultados } \\
\text { específicos de pesquisa, sendo } \\
\text { que neste acaso são os resultados de } \\
\text { outras pesquisas. }\end{array}$ & $\begin{array}{l}\text { Ainda não descrito em } \\
\text { pesquisas anteriores. }\end{array}$ \\
\hline
\end{tabular}

A observação de quais passos se fazem presentes em cada um dos projetos (Tabela 3) evidencia que não há nenhum presente em todos os projetos, sendo mais recorrentes os passos P1, P2, P4 e P12. Esse dado justifica por si mesmo a impossibilidade de falar, com base nesta amostra, 
em passos obrigatórios para essa seção ou em um modelo de organização retórica. Além disso, não há nenhum caso de duas seções que possuam exatamente os mesmos passos distribuídos numa mesma sequência, o que indica se tratar de uma seção cuja organização retórica é bastante instável e pouco convencionada.

TABELA 1 - Ocorrência de passos na seção de justificativa de pré-projetos de mestrandos em letras

\begin{tabular}{|c|c|c|c|c|c|c|c|c|c|c|c|c|}
\hline Projeto de pesquisa & P1 & P2 & P3 & $\mathbf{P} 4$ & P5 & P6 & P7 & P8 & P9 & P10 & P11 & P12 \\
\hline 1GR2012 & + & - & - & - & + & - & - & - & + & - & - & - \\
\hline 2GR2013 & + & - & - & + & - & + & - & - & - & - & - & + \\
\hline 3GR2014 & - & + & - & - & - & - & - & - & + & - & - & - \\
\hline 4GR2014 & + & + & + & - & + & + & - & - & - & - & - & - \\
\hline 5GR2014 & - & + & - & - & - & - & - & - & - & + & - & - \\
\hline 6GR2014 & - & - & + & + & + & + & - & - & - & - & - & - \\
\hline 7LEX2014 & + & + & + & + & - & + & - & - & + & - & - & - \\
\hline 8AD2012 & + & - & - & - & - & - & + & + & - & - & - & + \\
\hline 9AD2013 & - & + & - & - & - & + & + & - & - & - & - & + \\
\hline 10AD2013 & - & + & - & - & - & - & - & + & - & - & + & + \\
\hline 11AD2013 & + & + & - & + & - & - & - & - & - & - & + & - \\
\hline 12AD2013 & + & - & - & - & - & - & - & - & - & - & - & - \\
\hline 13AD2013 & + & + & - & + & - & - & - & + & - & - & - & - \\
\hline 14AD2014 & + & - & - & - & - & - & - & - & - & - & + & - \\
\hline 15AD2014 & + & + & - & - & - & - & - & + & + & - & + & + \\
\hline 16LET2012 & + & - & - & + & - & + & - & - & - & + & - & + \\
\hline 17LET2012 & - & + & + & - & - & - & - & - & - & + & + & + \\
\hline 18LET2013 & - & + & - & + & - & - & + & - & - & + & - & - \\
\hline
\end{tabular}




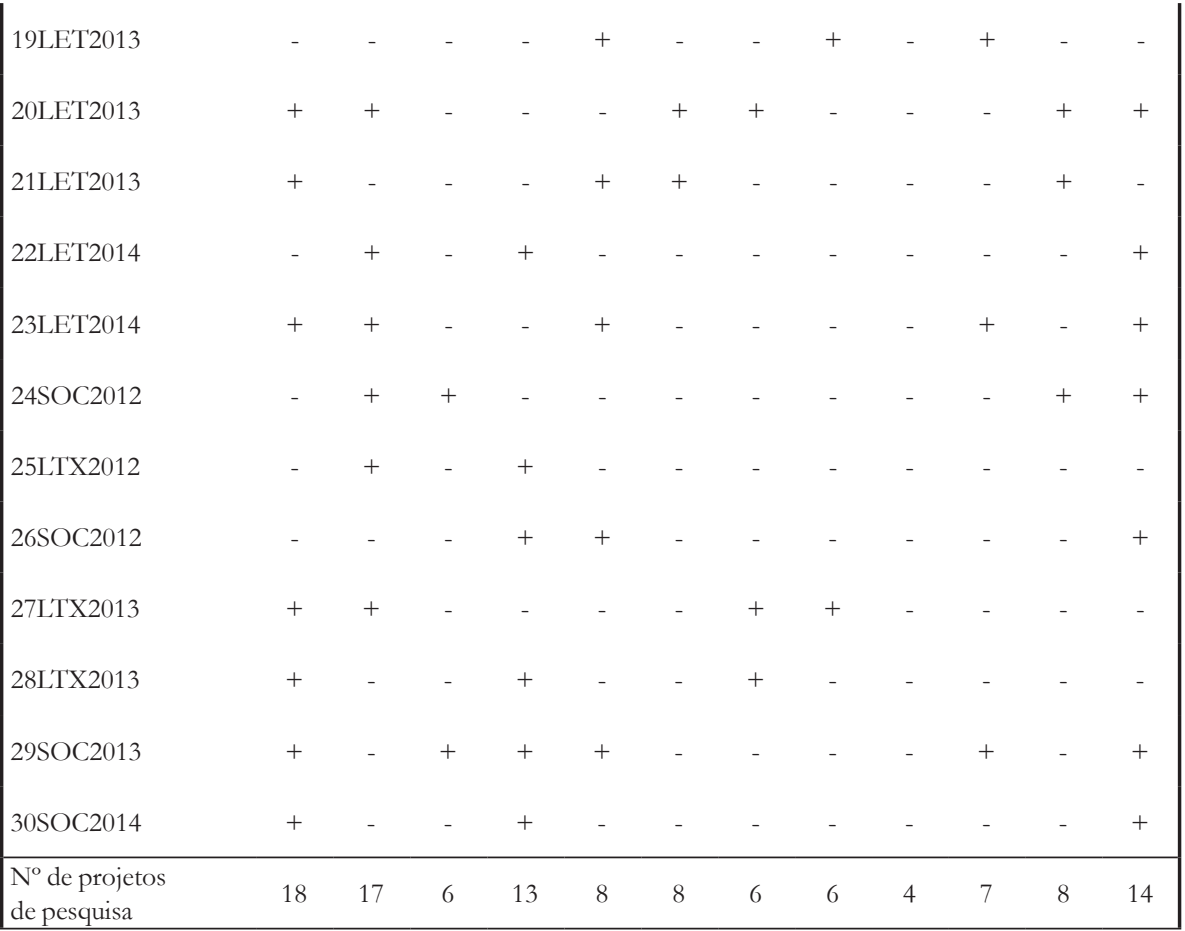

A análise quantitativa da ocorrência dos passos (Gráfico 1), computando-se inclusive mais de uma ocorrência em cada projeto, destaca o fato de, entre os mais recorrentes, haver passos que são esperados e típicos de outras seções de um pré-projeto (como as seções de objetivos, fundamentação teórica e metodologia) e/ou de outras seções de outros gêneros acadêmicos (caso de discussão e conclusões em artigos, dissertações, teses), conforme a Tabela 3. Essa diversidade de passos impõe à seção de justificativa uma saliente heterogeneidade retórica e pragmática, tendo em vista a diversidade de funções comunicativas associadas aos passos nela presentes. Isso termina por imprimir à seção de justificativa funções retóricocomunicativas típicas de resumos e introduções de gêneros acadêmicos, especificamente em relação à função de servir como um retrato condensado prévio de um texto extenso a vir à frente. Noutros termos, tal configuração faz com que a seção de justificava não se destine prioritariamente a justificar uma proposta de pesquisa a ser empreendida, mas principalmente a resumir a proposta global anunciando alguns dos seus principais elementos. 
GRÁFICO 1 - Ocorrências dos passos retóricos nos pré-projetos

\section{Ocorrência dos passos na seção de justificativa nos 30} projetos

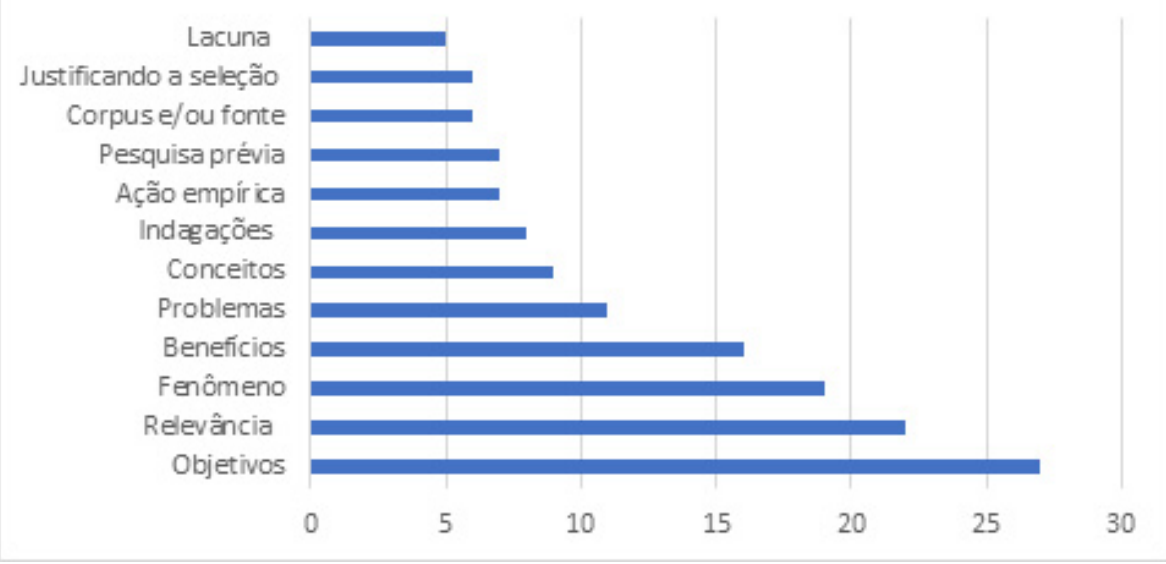

QUADRO 4 - Passos e seções onde tipicamente ocorrem passos retóricos

\begin{tabular}{|l|l|}
\hline \multicolumn{1}{|c|}{ Passo } & \multicolumn{1}{c|}{ Seção onde tipicamente ocorre } \\
\hline Indicando objetivos & Objetivos \\
\hline Explicando fenômenos & $\begin{array}{l}\text { Fundamentação teórica e seção de Discussão (de artigos, } \\
\text { dissertações, teses) }\end{array}$ \\
\hline Definindo conceitos & Fundamentação teórica \\
\hline Definindo corpus e/ou fonte de pesquisa & Metodologia \\
\hline Justificando a seleção do corpus & Metodologia \\
\hline Recomendando ação empírica & Conclusões (de artigos, dissertações, teses) \\
\hline
\end{tabular}

Um achado importante da pesquisa é que o passo mais recorrente na amostra é Indicando objetivos da pesquisa, o qual se faz presente em 27 das trinta seções analisadas. Tendo em vista haver nos pré-projetos uma seção específica apenas para expressão dos objetivos geral e específicos da proposta de pesquisa, a presença desse passo, na maioria absoluta das seções de justificativa, indica a centralidade dos objetivos para a elaboração 
da seção de justificativa. Noutras palavras, a ação de justificar a pesquisa depende, em parte, da reafirmação dos objetivos da proposta, como se houvesse uma concepção subjacente a dizer que o fato de haver objetivos, algo a ser alcançado ao final da ação de investigação, atestasse que a pesquisa é justificável. É muito provável que a reiteração dos objetivos em mais de uma seção assuma um caráter persuasivo, tendo em vista que informações repetidas possuem um status de relevância acentuada. É o que ocorre em P4: GR2014 e P30: SOC2014, cujas sequências consistem em retomar a apresentação dos objetivos que serão novamente mencionados na seção própria de objetivos:

A proposta desta pesquisa centraliza-se na análise de conceitos/ definições e descrição metalinguística, em âmbito morfológico, em gramáticas tradicionais "mercadológicas", que são as mais bem aceitas no mercado editorial, ou seja, as de maior tiragem. (P4: GR2014)

$\mathrm{Na}$ perspectiva da sociolinguística variacionista e interacional, bem como da etnografia linguística, este estudo pretende, através da análise quantitativa e qualitativa dos falares de membros da Associação de Moradores do bairro Campo de Belém, com sede no município de Caxias, Maranhão, evidenciar como o uso de aspectos da norma culta, inserido em registros predominante populares, aproxima estes falantes das instituições sociais, porque se ajusta à formalidade mediante o emprego da variedade de prestígio, ao tempo em que comunica com eficiência seus propósitos juntos aos usuários exclusivos da variedade popular. (P30: SOC2014)

Quando observamos os passos menos recorrentes na amostra, o que chama a atenção, pelo fato de divergir de expectativas em relação ao modo como pesquisadores elaboram projetos de pesquisa, é a baixa recorrência do passo Indicando lacunas de pesquisa (cinco ocorrências nos trinta projetos) - mais baixa inclusive do que passos típicos da seção de metodologia, como Justificando a seleção de corpus, fontes ou sujeitos (seis ocorrências nos trinta projetos) - e Delimitando corpus e/ ou fonte do corpus da pesquisa (seis ocorrências nos trinta projetos). Se contrastamos a baixa ocorrência do passo Indicando lacuna com a alta recorrência do passo Explicando fenômenos e, se levamos em conta que ambos são formulados a partir da leitura de outras fontes bibliográficas, podemos supor a presença de objetivos de leitura pouco congruentes com 
as finalidades típicas de seções de justificativa e mais congruentes com objetivos de leitura tipicamente "escolares", como ler para resumir ou resenhar textos. Esse contraste pode ser tomado como uma confirmação da ideia de que a complexidade retórica e discursiva dos projetos ao, por exemplo, incluir críticas e apoio na tradição, não é aprendida facilmente por novatos. A opção por explicar fenômenos com base na tradição ao invés de apontar lacunas indica que os mestrandos, como membros ainda periféricos na comunidade acadêmica, se inclinam para o polo da confirmação de ideias e não de sua contestação.

GRÁFICO 2 - Extensão dos passos na amostra total

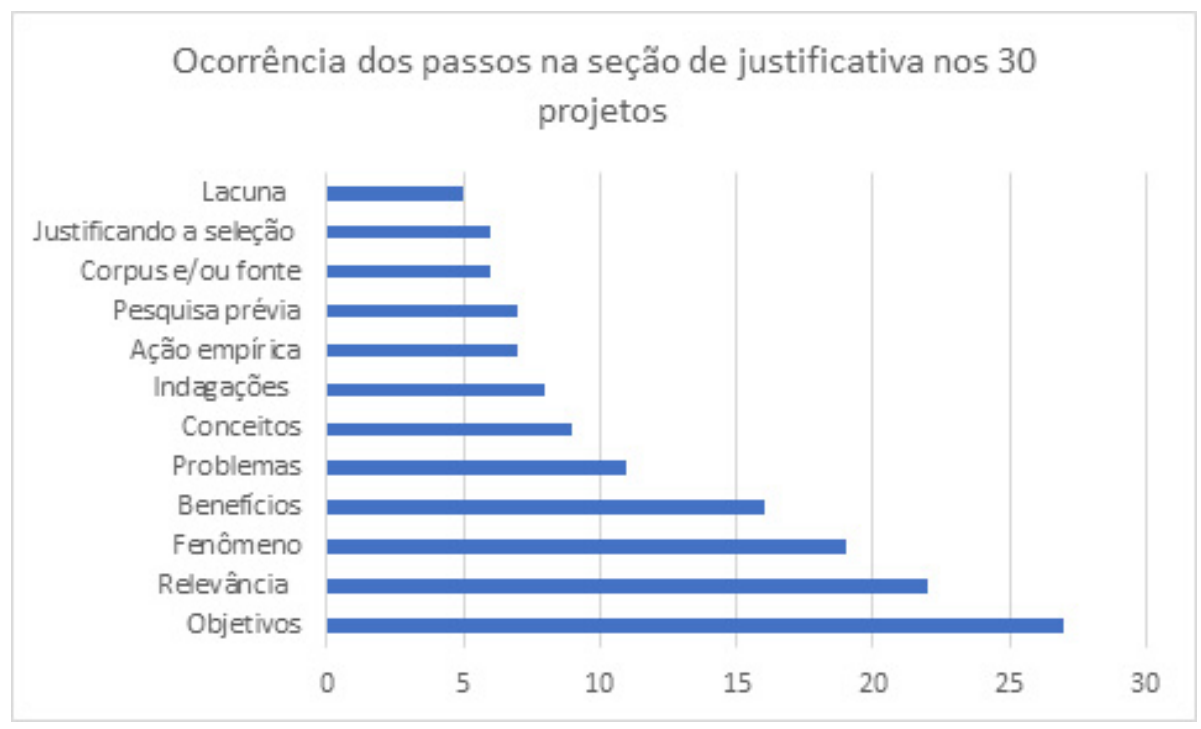

A análise acerca da extensão dos passos retóricos em toda a amostra (Gráfico 2) indica que justificar a relevância do projeto, oferecer explicações para fenômenos e indicar objetivos da pesquisa são os mais desenvolvidos em termos de quantidade de informação. Esses mesmos três passos são também os mais recorrentes no corpus, o que indica haver congruência entre o modo como os escritores concebem que passos devem mais estar presentes e quais devem ser mais desenvolvidos em termos de extensão. Noutras palavras, justifica-se uma pesquisa aqui apoiandose sobretudo em sua relevância, em seus objetivos e em explicações já consolidadas sobre certos fenômenos relacionados ao objeto da pesquisa. 
Um achado importante da pesquisa é a alta recorrência do passo Explicando um fenômeno empírico (dezenove ocorrências em trinta projetos) e sua relevância em termos de extensão (1.719 palavras em todo o corpus). A surpresa decorre do fato de esse passo não fazer parte das descrições anteriores de projetos de pesquisa - a exemplo de Connor e Mauranen (1999) e Jucá (2006) - nem de manuais de escrita de projetos (CIRIBELLI, 2000; BARROS, 2005). Associado a isso, podemos evocar o fato de que o discurso sobre projetos de pesquisa enfatiza a necessidade de reconhecer problemas, identificar lacunas de pesquisa, formular indagações e levantar hipóteses, pouco importando apresentar explicações neste estágio da pesquisa. Contrariando a retórica sobre a ciência que afirma que a admissibilidade da ignorância é a mola do conhecimento (HARARI, 2015), a retórica nas seções de justificativas pouco se volta para o que ainda não se sabe, preferindo ir na direção contrária ao relatar as explicações já disponíveis para os fenômenos sob investigação. Em P10: AD2013, num projeto que analisa o discurso do poeta Torquato Neto, a seção de justificativa já oferece explicações acerca de tal discurso, enfatizando o que o escritor conhece sobre a temática, mas não enfocando o que ainda não se sabe ou pouco se sabe.

Torquato remete ao discurso a sua subjetividade de autor, até mesmo no uso que ele faz do próprio gênero jornalístico, uma vez que apresenta uma mescla de discursos, ou seja, uma ruptura estilística. Denotamos, assim, uma postura vigilante, crítica e transgressora no uso feito da linguagem, a mídia, nesse caso, é abordada como um acontecimento vivo, e o discurso jornalístico como um produto da resistência do autor. (P10: AD2013)

Em P15: AD2014, enxerto de um projeto que analisa os imaginários sociais de corrupção política no discurso midiático e as entrevistas de candidatos à presidência do Brasil em 2014 no Jornal Nacional, vemos a presença de uma explicação para o modo como as entrevistas são usadas pelos candidatos. $O$ trecho revela o conhecimento que o escritor já possui acerca daquilo que deseja investigar. Ou seja, o conhecimento não é problematizado ou relativizado, mas reafirmado e assegurado. 
As entrevistas trazem consigo as marcas de vários papéis sociais assumidos pelo enunciador que acabam por representar camadas diversas da comunidade sendo reveladas através da construção de sua enunciação, que, pelo gênero dialogado que a veicula, acaba envolvendo de forma argumentativa e retórica a fala dos candidatos. (P15: AD2014)

O passo Explicando um fenômeno ocorre quando se objetiva oferecer explicações para fenômenos diversos da vida real associados, aqui neste contexto, a questões de linguagem. Os escritores mencionam conhecimento já disponível em outros estudos que se mostram eficazes para explicar algo relacionado ao que será pesquisado. É um passo que ocorre com frequência nas seções de discussão e de conclusão de diversos gêneros acadêmicos e de pesquisa. Em P22: LET2014, ao discutir o papel da escola como agência de letramento, apresenta-se uma assertiva ("a prosperidade... depende de como a escola protagoniza a relação ensino e aprendizagem com o mundo fora de seus muros") com a finalidade de explicar quais condições educacionais possibilitam a "prosperidade" no mercado de trabalho.

Sabemos que a escola é a principal agência de letramento existente em nosso cenário social, dessa forma sendo representante legitimado do saber. Com isso entendemos que a prosperidade (no sentido de resolver situações envolvendo o uso da escrita e conseguir de alguma forma se inserir no mercado de trabalho) das pessoas, não só de bairros periféricos, mas de qualquer outro, depende de como a escola protagoniza a relação ensino e aprendizagem com o mundo fora de seus muros. (P22: LET2014)

Do modo como são formuladas, muitas sequências categorizadas como o passo Oferecendo explicações para fenômenos poderiam aparecer coerentemente em seções de discussão de resultados e/ou em conclusões (considerações finais) de artigos, dissertações ou teses. A alta recorrência desse passo leva a refletir sobre o tipo de ensino-aprendizagem por que passam os alunos no ensino básico e na graduação - se voltado para a busca de problematizar o conhecimento já acessível ou se focado na assimilação passiva desse conhecimento. Os dados aqui se inclinam claramente para a segunda opção, sobretudo se é levado em conta que comumente os alunos são avaliados em termos de demonstrar que reproduzem com clareza o que os autores clássicos formularam. 


\section{O passo Recomendando e/ou prescrevendo ação empírica ocorre}

quando se recomenda e/ou prescreve ações pragmáticas a serem tomadas por atores sociais a fim de resolver ou atenuar problemas da vida social. Ocorreu apenas nas subáreas de letramento (seis casos) e sociolinguística (um caso). Um exemplo é:

Para que essa "consciência leitora" se realize, é também preciso observar que tipo de conhecimento está sendo passado para esse aluno. Que concepções de leitura vêm de seus professores no ensino superior. E como este aluno está sendo "lapidado" no decorrer de seu curso. É necessária a reflexão do professor e do aluno, que será também professor ao final de sua graduação. A formação desses futuros docentes deve ser pensada como um processo, que, para acontecer, deverá ter objetivos e planejamento. (P23: LET2014)

O interessante desse passo retórico é que ele contém uma ação que tipicamente aparece em seções finais de gêneros acadêmicos quando os pesquisadores fazem certas recomendações relacionadas a descobertas já feitas. Contudo, ao aparecer em pré-projetos de pesquisa que ainda serão desenvolvidos, o escritor parece antecipar algo que ainda será investigado ou fazer uso de conhecimentos e pontos de vista prévios (o que explica o uso de modalizadores dêonticos, como "é também preciso observar que" e "deve ser pensada"). O fato de esse passo, na amostra, ocorrer essencialmente na área de letramento e vincular-se a pesquisas sobre ensino e aprendizagem de leitura e escrita, atesta o grau de engajamento político dos mestrandos na busca por intervir na realidade, mas, em parte, enfraquece o caráter de novidade de implicações e sugestões que poderiam advir apenas após o resultado da pesquisa.

O passo definindo conceitos possui uma natureza eminentemente teórica e visa definir um conceito recorrendo a autores clássicos da área. Tendo em vista que a ação de conceituar tipicamente é feita na seção de fundamentação teórica de diversos gêneros, esse passo, por vezes, se mostra pouco articulado aos demais passos da seção de justificativa e à função geral esperada de justificar a pesquisa a ser desenvolvida. É muito provável que este passo se articule à necessidade do escritor de demonstrar para a banca avaliadora do projeto que ele possui conhecimento sobre os conceitos essenciais de sua pesquisa, o que deporia a favor de ele ser considerado apto a ingressar na pós-graduação. Em P14: AD2014, o termo subjetividade é 
definido duas vezes, por meio de apoio em autor de referência na área, além de haver ainda uma definição para subjetividade niilista.

A subjetividade aqui entendida é a mesma que Benveniste (2005, p. 286) define como sendo: “... a capacidade do locutor para se propor como sujeito, definida como unidade psíquica que transcende a totalidade das experiências vividas que reúne e que assegura a permanência da consciência". $\mathbf{O}$ autor a define ainda como nada mais que a emergência do ser na linguagem. A subjetividade se relaciona à pessoa. O sujeito que se pretende analisar é aquele que se apresenta como eu em seu discurso. A subjetividade niilista que interessa a este trabalho é a que caracteriza o sujeito na concepção que Vitor de Sá (1991) define como negação absoluta em que o aniquilamento é o fim supremo da vida. O mesmo autor afirma que os niilistas foram revolucionários russos emergidos na segunda metade do século XIX e que lutaram contra o absolutismo na Rússia czarista. Em sua contextualização do niilismo, Sá (1991) afirma que o niilismo teria sido um movimento filosófico e literário que floresceu após a libertação dos servos russos por volta de 1860. (P14: AD2014)

O outro passo ainda não descrito para seção de justificativa é Apresentando indagações de pesquisa, embora ele seja previsto em manuais sobre escrita de projetos. Segue um exemplo:

Este, segundo Charaudeau (2013) pertence ao domínio das representações sociais, bem como sua valorização no domínio político depende das circunstâncias. A fim de identificar as estratégias utilizadas através do ethos de um sujeito político, criam-se indagações pertinentes: o que faz definir quais tipos de ethé será construído em uma campanha eleitoral? Para analisar os ethé de um sujeito político deve-se considerar apenas seu discurso? Quando um político elide uma questão ou refuta, colocando sua imagem diante da cena? (P6: 9AD2013)

A análise empreendida sugere que a seção de justificativa é construída como tendo uma função global muito semelhante ao que apresentam as introduções de diversos gêneros acadêmicos, qual seja apresentar, em síntese, um panorama das várias informações que comporão o texto completo. Isso é evidenciado pelo fato de haver passos retóricos típicos de seções de objetivos, referencial teórico, metodologia, discussão e conclusão. Tudo leva a se pensar que o principal propósito comunicativo da seção de justificativa 
não é exatamente justificar a pesquisa a ser empreendida, mas proceder a uma introdução do texto completo da pré-projeto.

\section{Considerações finais}

O estudo aqui realizado mapeou concepções de mestrandos acerca do que constituem as ações retóricas que se incorporam na elaboração de seções de justificativa de pré-projetos de pesquisa. Após optar por uma descrição tomando por base a noção de passo retórico, com exclusão da noção de movimento retórico, foi possível reconhecer a presença de três passos ainda não descritos na literatura sobre esta seção, quais sejam: definindo conceitos, explicando fenômenos e rescrevendo e/ou recomendando ação empírica. A presença recorrente desses três passos pode ser justificada por um cenário educacional que habilita os alunos muito mais para se apropriar do conhecimento já estabelecido e revozeá-lo do que para questionar este conhecimento, valorizar o que não sabe e buscar lacunas para o que é ignorado.

Uma reflexão importante decorrente da análise tem a ver com as funções a que atendem as leituras bibliográficas feitas pelos alunos e comentadas nos projetos, uma vez que a apropriação de uma fonte bibliográfica pode dar ensejo a diversos passos retóricos, como indicar lacuna, reportar pesquisa prévia, definir conceitos, explicar fenômeno e indicar indagações de pesquisa. Desses cinco passos, os menos usados na amostra foram indicar lacuna, reportar pesquisa prévia e indicar indagações de pesquisa, enquanto os mais usados foram definir conceitos e explicar fenômeno. Isso sugere que as leituras são compreendidas como mais associadas à busca pelo conhecimento estabelecido (pela "verdade") e menos associadas à descoberta daquilo que ainda é ignorado ou problemático.

Uma implicação pedagógica importante da pesquisa diz respeito ao aprendizado e tomada de consciência acerca das funções da leitura voltadas para o universo da pesquisa. Tudo indica que entre os escritores dos projetos aqui analisados prevalecem práticas de leituras voltadas para a compreensão de conceitos e para a explicação de fenômenos e, em contrapartida, são escassas as práticas de leitura para reconhecer lacunas de pesquisa, formular problemas de pesquisa e relatar o desdobramento de uma tradição de pesquisa. Em face de tal constatação parece necessário 
difundir entre os graduandos práticas de leitura bibliográficas focadas em necessidades específicas do processo de elaboração de propostas de pesquisa, especialmente no que se refere à busca pelo desconhecido, pelo que é ignorado e pelas explicações que ainda se mostram incompletas ou insuficientes.

Tendo em vista esta pesquisa usar como amostra um universo muito pequeno e restrito a uma única universidade pública, mais pesquisas precisam ser feitas para investigar se as concepções aqui descobertas ocorrem em outros contextos. Além disso, pesquisas etnográficas focadas em perceber como ocorrem os processos de escrita e leitura de mestrandos podem lançar luz sobre as causas das questões aqui elencadas.

\section{Agradecimentos}

Ao CNPQ, através do Edital Universal/2014. À UFPI, através do Edital Bolsa de Produtividade em Pesquisa UFPI/PROPESQ - PRPG. Ao meu bolsista de PIBIC Leonardo Cunha, pelo auxílio na organização dos dados.

\section{Referências}

ASKEHAVE, I.; SWALES, J. Identificação de gênero e propósito comunicativo: um problema e uma possível solução. In: BEZERRA, B. G. et al. (Org.). Gêneros e sequências textuais. Recife: Edupe, 2009. p. 221-247.

AUSTIN, J. Quando dizere é fazer. Trad. Danilo Marcondes de Souza Filho. Porto Alegre: Artmed, 1990.

BARROS, J. D. Oprojeto de pesquisa em história: da escolha do tema ao quadro teórico. 2. ed. Petrópolis: Vozes, 2005.

BAZERMAN, C. Gêneros textuais: tipificação e interação. São Paulo: Cortez, 2005. BERKENKOT'TER, C; HUCKIN, T. N. Genre knowledge in disciplinary communication: cognition/culture/power. Mahwah: Lawrence Erlbaum Associates, 1995.

BHATIA, V. K. Worlds of written discourse: a genre-based view. London: Continuum, 2004.

CIRIBELLI, M. C. Projeto de pesquisa: um instrumental da pesquisa científica. Rio de Janeiro: 7 Letras, 2000.

CONNOR, U. Variation in rhetorical moves in grant proposal of US humanists and scientists. Text $\approx$ Talk, Berlin, v. 20, n. 1, p. 1-25, 2000. DOI: https://doi. org/10.1515/text.1.2000.20.1.1 
CONNOR, U.; MAURANEN, A. Linguistic analysis of grant proposals: European Union research grant. English for Specific Purpose, Amsterdam, v. 18, n. 1, p. 47-62, 1999. DOI: https://doi.org/10.1016/S0889-4906(97)00026-4

CONNOR, U; UPTON, T. A., The genre of grant proposals: a corpus linguistic analysis. In: CONNOR, Ulla;UPTON, Thomas A. (Ed.). Discourse in the Professions: Perspectives from Corpus Linguistics. Amsterdam: John Benjamins, 2004. p. 235255. DOI: https://doi.org/10.1075/scl.16.10con

FENG, H. A genre-based study of research grant proposals in China. In: CONNOR, U.; NAGELHOUT, E.; ROZYCKI, W. (Ed.). Contrastive rhetoric. Amsterdam: John Benjamins, 2008. DOI: https://doi.org/10.1075/pbns.169.07fen FENG, H.; SHI, L. Genre analysis of research grant proposals. LSP \& Professional Communication, Frederiksberg, v. 4, n. 1, p. 8-32, 2004.

HARARI, Y. N. Homo sapiens: uma breve história da humanidade. Porto Alegre: L\&PM, 2015.

JUCÁ, D. C. N. A organização retórico-argumentativa na seção de justificativa no gênero textual projeto de dissertação. 2006. 109f. Dissertação (Mestrado em Letras) -Universidade Federal do Ceará, Fortaleza, 2006.

LEITÃO, P. A apreensão do gênero projeto de pesquisa por alunos do curso de licenciatura em letras. 2008. 204f. Dissertação (Mestrado em Linguística) Universidade Federal da Paraíba, Paraíba, 2008.

MONTEIRO B. N. Organižação retórica e estruturação sequencial da sȩ̧ão de metodologia do gênero projeto de pesquisa. 2016. Dissertação (Mestrado em Letras) - Universidade Federal do Piauí, Teresina, 2016.

MOTTA-ROTH, D.; HENDGES, G. R. Produção textual na universidade. São Paulo: Parábola Editorial, 2010.

MYERS, G. The social construction of two biologists' proposals. Written Communication, Sage Journals, v. 2, n. 3, p. 219-245, 1985. DOI: https://doi. org $/ 10.1177 / 0741088385002003001$

RIO LIMA, C. A. Movimentos retóricos na seção de fundamentação teórica de projetos de pesquisa na subárea de Linguística. Teresina: Pibic, 2015.

SILVA, C. R. B. Movimentos retóricos da seção de justificativa de pré-projetos de pesquisa da subárea de Linguística. Teresina: Pibic, 2015.

SWALES, J. M. Aspects of article introductions. Birmingham: The University of Aston, 1981

SWALES, J. Genre analysis: English in academic and researching settings. Cambridge: Cambridge University Press, 1990. 
SWALES, J. M. Research genres: explorations and applications. Cambridge: Cambridge University Press, 2004. DOI: https://doi.org/10.1017/CBO9781139524827

TARDY, C. M. A genre system view of the funding of academic research. Written Communication, Sage Journals, v. 20. n. 1, p. 7-36, 2003. DOI: https://doi. org/10.1177/0741088303253569

TSENG, M. The genre of research grant proposals: towards a cognitive-pragmatic analysis. Journal of Pragmatics, Elsevier, v. 43, n. 8, p. 2254-2268, 2011. DOI: https:/ / doi.org/10.1016/j.pragma.2011.02.015 